\title{
Erratum to: Deborah Lipsky, Will Richards: Managing Meltdowns: Using the S.C.A.R.E.D Calming Technique with Children and Adults with Autism
}

Jessica Kingsley, Philadelphia, PA, 2009, 80 pp., ISBN 978-1-84310-908-2.

$\$ 14.95$ (paper)

\section{Carla Mazefsky}

Published online: 2 December 2009

(C) Springer Science+Business Media, LLC 2009

Erratum to: J Autism Dev Disord

DOI 10.1007/s10803-009-0852-y

The publisher for the book reviewed here was incorrectly stated in the review. The publisher is Jessica Kingsley in Philadelphia, PA.

The online version of the original article can be found under doi:10.1007/s10803-009-0852-y.

C. Mazefsky $(\bowtie)$

Department of Psychiatry, Center for Excellence in Autism Research, University of Pittsburgh School of Medicine,

3811 O'Hara Street, Pittsburgh, PA 15213, USA

e-mail: mazefskyca@upmc.edu; carla.mazefsky@chp.edu 